\title{
Autologous Fat Grafting as a Last Resort for Unsustainable Pain in a Woman with Multiple Osteochondromas
}

\author{
Vera Lidwina Negenborn ${ }^{1}$, Esther Moerman ${ }^{1}$, Simon Johannes Ham ${ }^{2}$ \\ ${ }^{1}$ Department of Plastic, Reconstructive and Hand Surgery, Onze Lieve Vrouwe Gasthuis Oost, Amsterdam; ${ }^{2}$ MO-Expertise Center, \\ Department of Orthopaedic Surgery, Onze Lieve Vrouwe Gasthuis Oost, Amsterdam, The Netherlands
}

\begin{abstract}
Multiple osteochondromas (MO) is characterized by the formation of osteochondromas throughout the entire body. Although the evidence regarding its pathogenesis is well understood, no curative treatment for the disorder is available. Patients can be treated symptomatically by surgical removal of painful osteochondromas. Unfortunately, some patients still suffer from severe pain, even after surgery. We report on a case concerning a 48-year-old woman with a history of MO who presented with persistent pain after surgical removal of a symptomatic osteochondroma of the left scapula and multiple symptomatic osteochondromas of the left foot and trochanteric region. Several interventions to reduce the pain did not have any lasting effect. Subsequently, she was treated with autologous fat grafting (AFG). After each session she was pain-free for at least one year and reported only partial recurrence of the pain. This is the first case report describing AFG for the treatment of pain after both surgical removal of an osteochondroma and symptomatic osteochondromas in a patient suffering $\mathrm{MO}$ with promising results. The treatment is more effective and clearly continues to remain active longer than injection therapy or pain medication. Future studies are necessary to confirm our results.
\end{abstract}

Keywords Multiple hereditary exostoses / Adipose tissue / Pain management
Correspondence: Esther Moerman Department of Plastic, Reconstructive and Hand Surgery, Onze Lieve Vrouwe Gasthuis Oost, Oosterpark 9, 1091 AC Amsterdam, The Netherlands

Tel: +31-020-599-4903

Fax: +31-020-599-3818

E-mail: E.moerman@olvg.nl

We would like to acknowledge Dr. M.H. Haloua for helping us with selecting the radiological images.

No potential conflict of interest relevant to this article was reported.

Received: 31 Mar 2016 • Revised: 9 Aug 2016 • Accepted: 17 Aug 2016

pISSN: 2234-6163 • elSSN: 2234-6171 • https://doi.org/10.5999/aps.2017.44.2.162 • Arch Plast Surg 2017;44:162-165

\section{INTRODUCTION}

Multiple osteochondromas (MO) is characterized by the formation of cartilage-capped benign bone tumors that develop in the metaphysis of the long bones as well as in the axial skeleton, but not in the facial bones. Patients with MO often suffer from a wide variety of clinical manifestations, of which pain is one of the most common and disturbing symptoms [1-3]. To date, no curative or preventive treatment procedures exist for the disor- der itself, and often excision of symptomatic osteochondromas or limb reconstruction procedures are necessary $[3,4]$. Unfortunately, some patients still suffer from severe pain, even after surgical treatment, and do not respond sufficiently to pain medication. A new treatment option in these selected cases is autologous fat grafting (AFG), which has proved to be a useful method for the reduction of different types of pain [5-8]. In this case study, we present a patient with $\mathrm{MO}$ treated with autologous fat grafting for persistent pain after both surgical removal of an os- 
teochondroma and symptomatic osteochondromas.

\section{CASE}

A 48-year-old woman with a history of MO presented at our outpatient clinic with persistent pain after intensive treatment for symptomatic osteochondromas. In the past, multiple surgical procedures had been performed, including excision of osteochondromas located at the knees, left scapula, and left foot. At presentation, she complained of a painful and residual, though very small, osteochondroma originating from the left scapula, and persistent pain from symptomatic osteochondromas at the 5th digit of the left foot and in the trochanter region (Figs. 1-3). Pain medication was not sufficient, and the effect of multiple corticosteroid injections in both her left scapular region and trochanteric region only lasted for a few weeks. Because previous treatment, including surgical removal of the osteochondroma, local injection therapy with corticosteroids, and analgesics, only had minimal effect for a limited period, we decided to treat her with autologous fat grafting.

The adipose tissue was collected from the abdomen and inner thigh after infiltration with sodium chloride $0.9 \%$ mixed with $2 \%$ lidocaine $(2 \mathrm{mg} / \mathrm{mL})$ and 1-milliliter epinephrine $(1 \mathrm{mg} /$ $\mathrm{mL})$. It was then centrifuged at 3,000 rpm for 5 minutes. The central layer, consisting of usable fat, was then separated from the upper layer (oil) and lower layer (blood and liquid infiltrations) and injected into the body. During the first operation, 70

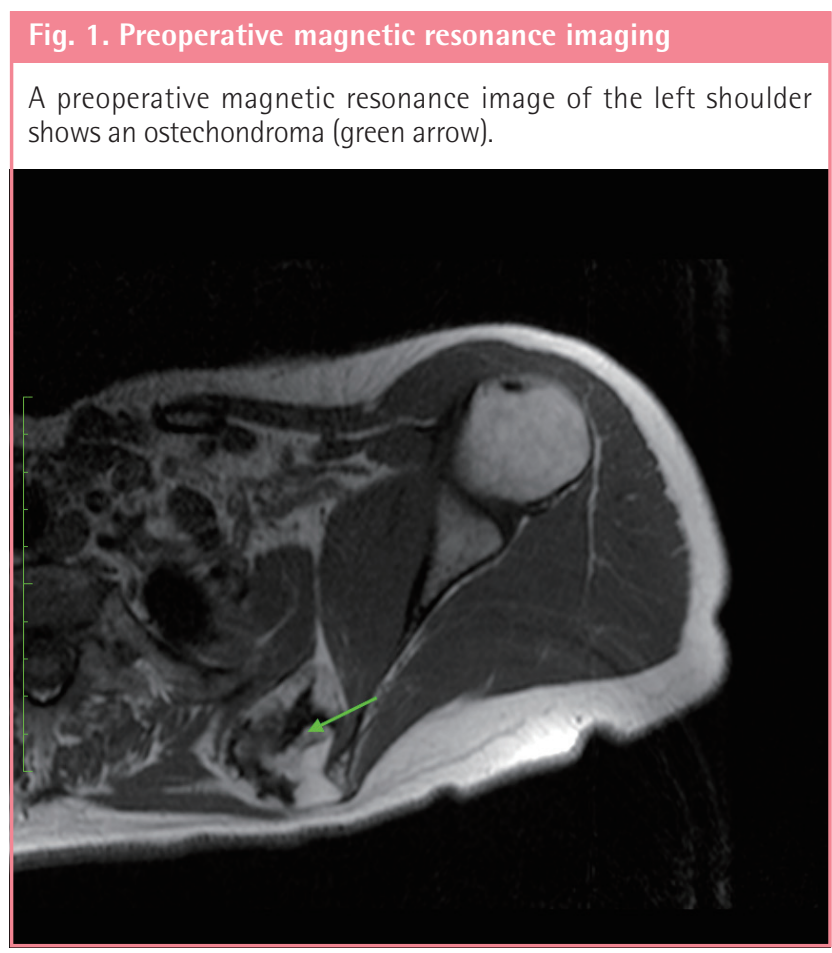

cc autologous fat was harvested from the abdomen and injected into the painful region of her left scapula. The patient was very satisfied with the result and she experienced relief of her pain for

\section{Fig. 2. Postoperative magnetic resonance imaging \\ A postoperative magnetic resonance image of the left shoulder af- ter surgical removal of the osteochondroma shows a small residual osteochondroma (green arrow).}

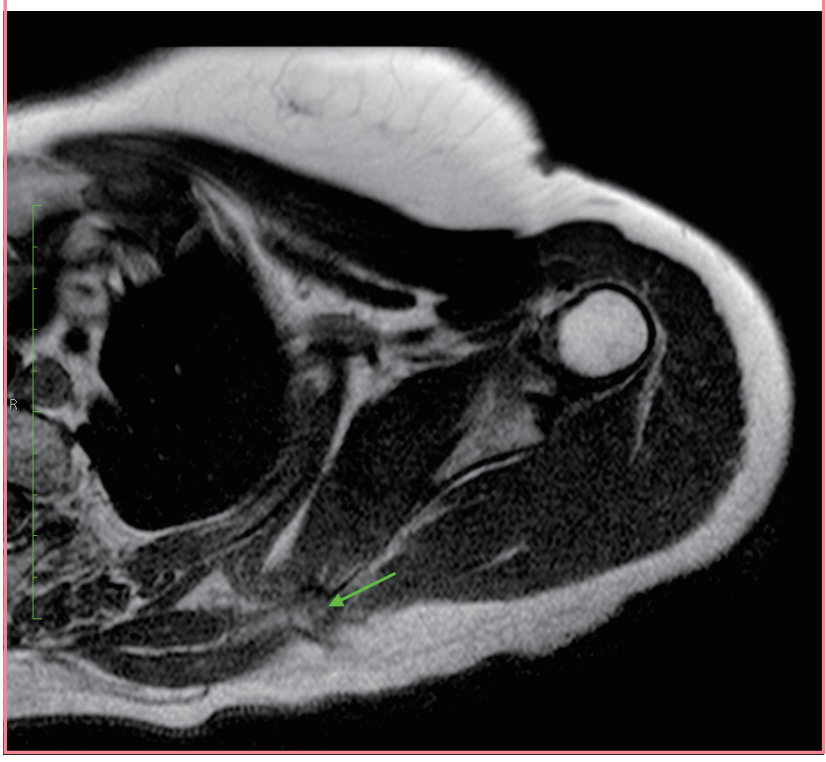

\section{Fig. 3. Postsurgical $X$-ray}

An X-ray of the left foot with a small osteochondroma at the lateral side of the distal phalanx of digit 5 (green arrow), after surgical removal of an osteochondroma at the lateral side of digit 4 .

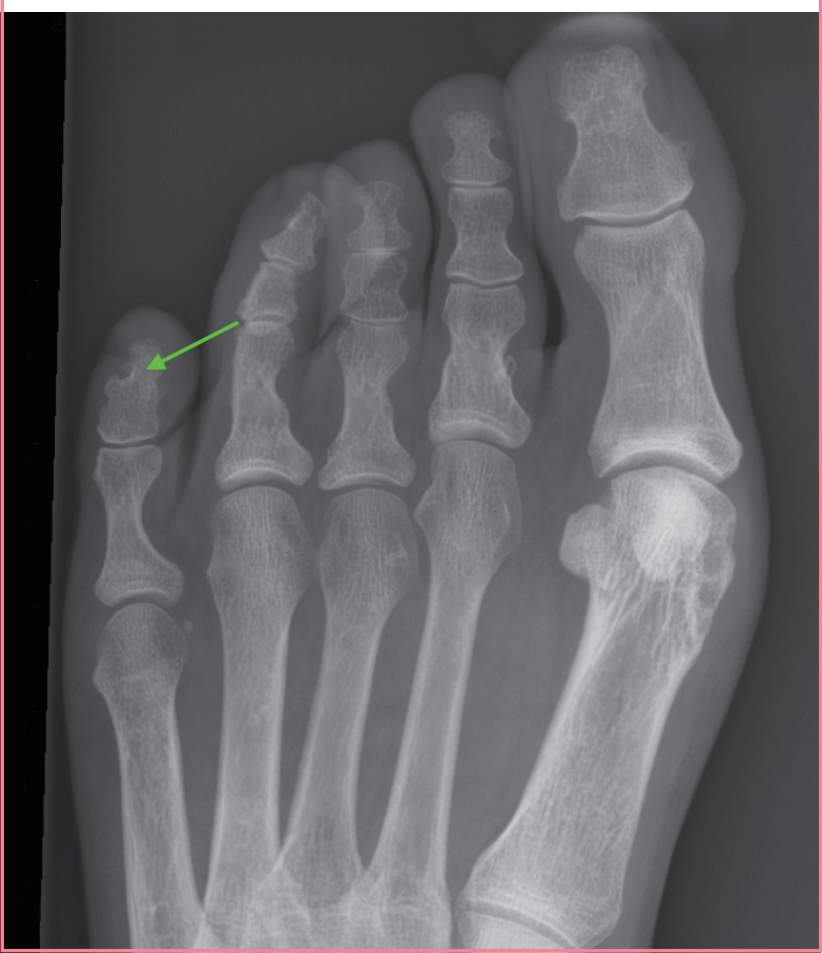




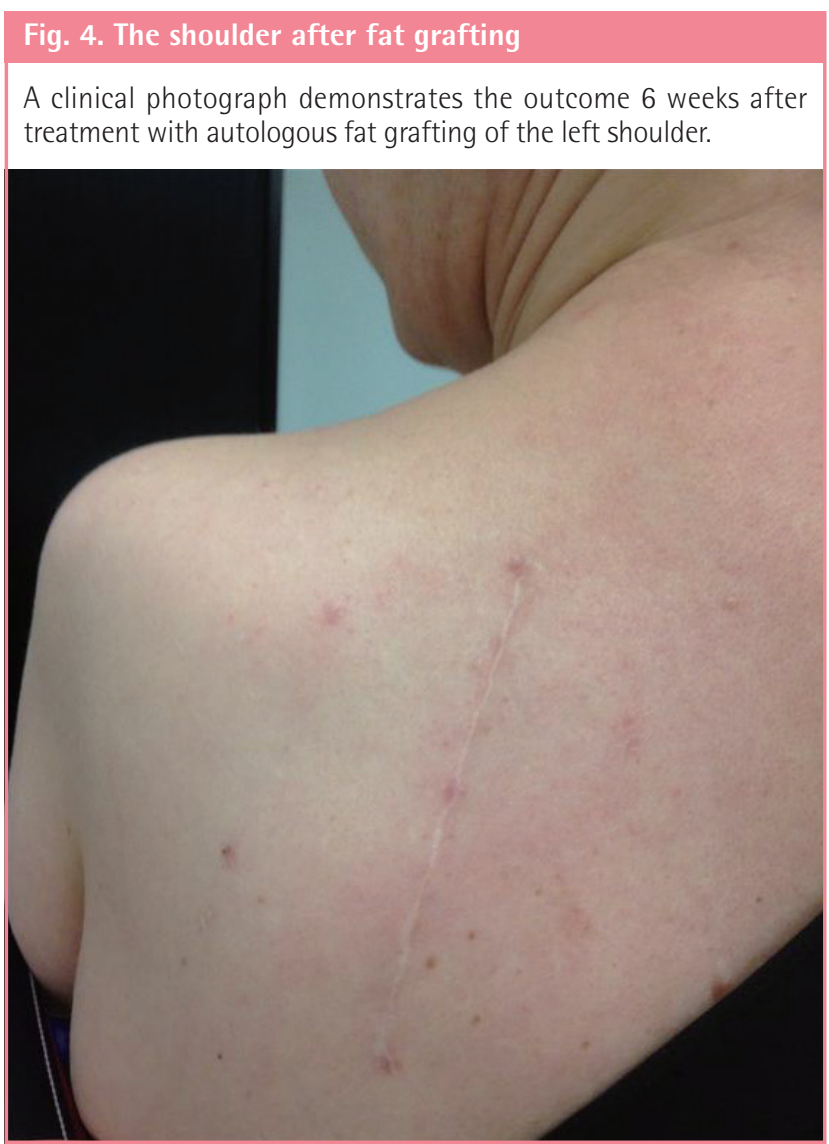

1 year. Subsequently, surgery was repeated 1 year later and 51 $\mathrm{mL}$ autologous fat from the abdomen and flanks was injected into her left scapula as well as $2 \mathrm{~mL}$ into the 5 th digit of the left foot. This procedure was repeated again 1 year later with harvested fat from the abdomen and an injection of $60 \mathrm{~mL}$ into the left scapula, $3 \mathrm{~mL}$ into the left foot, and $12 \mathrm{~mL}$ autologous fat into both trochanter regions. The postoperative courses were uneventful, besides hematomas at the donor site (Fig. 4). She reported a 5-step reduction in pain according to the visual analogue scale (from 8 to 3 ), and she was able to stop taking pain medication during and following these years of treatment. After the treatment, she reported only partial recurrence of the pain, which was also not as severe as before the treatment.

\section{DISCUSSION}

MO, previously known as multiple hereditary exostoses, is an autosomal dominant inherited disorder. The disorder was first described by Hunter in 1,786 [8,9]. It is caused by loss-of-function mutations in either the exostosin-1 (EXT1) or exostosin-2 (EXT2) gene. EXT1 and EXT2 mutations have been identified in over $90 \%$ of the affected individuals [1,9-11]. Medical and family history can be a clue for diagnosis, and full radiological and histological examinations will confirm it. The prevalence is estimated at 1:50,000, but it is uncertain how many patients are actually affected $[1,11,12]$.

Although many osteochondromas can be asymptomatic, patients with $\mathrm{MO}$ can suffer from a variety of symptoms and problems $[4,8,9]$. The disorder can interfere with normal articular function, causing impaired movement, and limb deformities are often present, including growth disturbances, most notably in the forearm, limb length discrepancies, short stature, excessive knee and ankle valgus position, and hip joint dysplasia. Osteochondromas can also be cosmetically disfiguring [1]. More severe complications include spontaneous hemothorax, neurovascular and spinal cord compression, the formation of (pseudo-) aneurysms, and obstetric problems $[1,4]$. The most feared complication of $\mathrm{MO}$ is the malignant transformation of an osteochondroma into a chondrosarcoma $[11,12]$.

Pain is the most common and disturbing manifestation of the disorder [1-3,5]. In 2 major studies, pain was experienced by $76 \%$ and $84 \%$ of patients, with a negative influence on activities of daily living, mood, and sleep $[3,5,12,13]$. Furthermore, pain on a daily basis was reported in a considerable number of patients. Not surprisingly, pain is the most frequent indication for surgery and is often indicated in cases of evident compression of osteochondromas on surrounding tissues. However, satisfying results are not always achieved, and persistent pain might occur in some cases. Treatment with local injection therapy or analgesics is not always effective, and other treatment options should be available to these patients.

Autologous fat grafting (AFG) could be one of these options in selected cases. In autologous fat grafting, fat is harvested, processed, and transplanted to different parts of the body. It has proven a valuable treatment regimen in patients suffering from multiply determined chronic pain $[13,14]$. In previous studies, a significant reduction of pain was reported after treatment with AFG for patients with post-mastectomy pain syndrome $[6,7]$ or painful scars with a mean follow-up ranging from 10 to 14 months [5-8]. The mesenchymal cells of the fat graft are thought to give prolonged analgesia by changing the microenvironment and the secretion of substances $[6,7,13,14]$. In the literature, a resorption rate of $17 \%$ to $82 \%$ of the injected fat is reported [15], which could explain why repeated treatment is required.

This is the first case report describing AFG with promising results for the treatment of pain after both surgical removal of an osteochondroma and symptomatic osteochondromas in a patient with MO. The treatment is more effective and clearly remains active longer than the effect of injection therapy or pain medication. However, this report is limited by the inclusion of 
only 1 case. Future studies including more patients in a controlled setting are necessary to confirm our results.

\section{REFERENCES}

1. Ham SJ, de Lange J, van der Zwan AL, et al. Clinical problems in multiple osteochondroma. Ned Tijdschr Geneeskd 2012;156:A4254.

2. Stieber JR, Dormans JP. Manifestations of hereditary multiple exostoses. J Am Acad Orthop Surg 2005;13:110-20.

3. Darilek S, Wicklund C, Novy D, et al. Hereditary multiple exostosis and pain.J Pediatr Orthop 2005;25:369-76.

4. Ryckx A, Somers JF, Allaert L. Hereditary multiple exostosis. Acta Orthop Belg 2013;79:597-607.

5. Darilek S, Wicklund C, Novy D, et al. Hereditary Multiple Exostosis and Pain.J Pediatr Orthop 2006;25:369-76.

6. Baptista C, Iniesta A, Nguyen P, et al. Autologous fat grafting in the surgical management of painful scar: preliminary results. Chir Main 2013;32:329-34.

7. Caviggioli F, Maione L, Forcellini D, et al. Autologous fat graft in postmastectomy pain syndrome. Plast Reconstr Surg 2011;128:349-52.

8. Klinger M, Caviggioli F, Klinger FM, et al. Autologous fat graft in scar treatment. J Craniofac Surg 2013;24:1610-5.

9. Solomon L. Bone growth in diaphysial aclasis. J Bone Joint Surg Br 1961;43:700-16.

10. Porter DE, Lonie L, Fraser M, et al. Severity of disease and risk of malignant change in hereditary multiple exostoses: a genotype-phenotype study. J Bone Joint Surg Br 2004;86: 1041-6.

11. Bovee JV. Multiple osteochondromas. Orphanet J Rare Dis 2008;3:3.

12. Sonne-Holm E, Wong C, Sonne-Holm S. Multiple cartilaginous exostoses and development of chondrosarcomas: a systematic review. Dan Med J 2014;61:A4895.

13. Goud AL, de Lange J, Scholtes VA, et al. Pain, physical and social functioning, and quality of life in individuals with multiple hereditary exostoses in The Netherlands: a national cohort study.J Bone Joint Surg (Am) 2012;94:1013-20.

14. Negenborn VL, Groen JW, Smit JM, et al. The Use of Autologous Fat Grafting for Treatment of Scar Tissue and ScarRelated Conditions: A Systematic Review. Plast Reconstr Surg 2016;137:31e-43e.

15. Zhou Y, Wang J, Li H, et al. Efficacy and Safety of Cell-Assisted Lipotransfer: A Systematic Review and Meta-Analysis. Plast Reconstr Surg 2016;137:44e-57e. 